\title{
Multi criteria decision making of machining parameters for Die Sinking EDM Process
}

\author{
G. K. Bose $\mathrm{a}^{*}$ and K. K. Mahapatra ${ }^{\mathrm{b}}$
}

${ }^{a}$ Department of Mechanical Engineering , Haldia Institute of Technology, Haldia 721657, India

${ }^{b}$ Technical Service, Central Institute of Plastic Engineering Technology, Bhubaneswar 751024, India

\section{H R O N I C L E \\ A B S T R A C T}

Article history:

Received July 92014

Received in Revised Format

October 232014

Accepted October 222014

Available online

October 302014

Keywords:

$E D M$

ANOVA

GRA

Material removal rate

Surface Roughness

Overcut

\begin{abstract}
Electrical Discharge Machining (EDM) is one of the most basic non-conventional machining processes for production of complex geometries and process of hard materials, which are difficult to machine by conventional process. It is capable of machining geometrically complex or hard material components, that are precise and difficult-to-machine such as heat-treated tool steels, composites, super alloys, ceramics, carbides, heat resistant steels etc. The present study is focusing on the die sinking electric discharge machining (EDM) of AISI H 13, W.-Nr. 1.2344 Grade: Ovar Supreme for finding out the effect of machining parameters such as discharge current (GI), pulse on time (POT), pulse off time (POF) and spark gap (SG) on performance response like Material removal rate (MRR), Surface Roughness (Ra) \& Overcut (OC) using Square-shaped $\mathrm{Cu}$ tool with Lateral flushing. A well-designed experimental scheme is used to reduce the total number of experiments. Parts of the experiment are conducted with the L9 orthogonal array based on the Taguchi methodology and significant process parameters are identified using Analysis of Variance (ANOVA). It is found that MRR is affected by gap current $\& \mathrm{Ra}$ is affected by pulse on time. Moreover, the signal-to-noise ratios associated with the observed values in the experiments are determined by which factor is most affected by the responses of MRR, Ra and OC. These experimental data are further investigated using Grey Relational Analysis to optimize multiple performances in which different levels combination of the factors are ranked based on grey relational grade. The analysis reveals that substantial improvement in machining performance takes place following this technique.
\end{abstract}

\section{Introduction}

Electrical Discharge Machining (EDM) has acquired impetus in the field of nontraditional machining because of its extensive industrial applications. Here the material removal takes place by controlled erosion through a series of electric sparks amid the tool - electrode and the work piece (Ghosh \& Mallick, 1991). The thermal energy of the sparks leads to extreme heating on the work piece resulting in melting and vaporization. It has made simple the machining of intricate shapes and even in difficult to cut materials (El Hofy, 2005). This process is being used widely in press tools and dies, aerospace, automotive, surgical components manufacturing industries etc. EDM has been established to be applicable to machine electrically conductive materials such as stainless steels, tool steel, carbides, super alloys, ceramic etc. in spite of their other physical and metallurgical properties (HO \& Newman, 
2003). The quality of the machined parts in EDM is significantly affected by control parameters (Yan et al. 2005). Optimal machining conditions are accomplished by executing a detailed analysis of all the factors affecting the process and also the interactions between them. The major factors influencing EDM process are Pulse on time (POT), Pulse off time (POF), Spark gap (SG), Gap current (GI), etc. and physical properties of electrode, work piece and dielectric fluid (Kiyak \& Cakir, 2007). Design of experiments (DOE) methods has been used quite effectively in industrial applications to optimize manufacturing processes (Varun et al., 2012). On the other hand DOE can locate the best set of precise process parameter level combinations with distinct values. In the Sinker EDM process, two metal parts submerged in an insulating liquid are connected to a source of current which is switched on and off automatically depending on the parameters set on the controller (Nadam et al., 2012).

Debroy and Chakraborty (2013) reviewed the applications of different non-conventional optimization techniques for parametric optimization of NTM processes. It is observed that EDM processes have been optimized most number of times, followed by wire electrical discharge machining (WEDM) processes. In most of the cases, the past researchers have preferred to maximize material removal rate. Gupta and Kumar (2013) optimized the performance characteristics such as surface roughness and material removal rate in unidirectional glass fiber reinforced plastic composites using Taguchi method and Grey relational analysis. Grey relation analysis was used to optimize the parameters and Principal Component Analysis is used to find the relative significance of performance characteristics. Sahoo and Mohanty (2013) presented the application of Taguchi's parameter design to optimize the parameters for individual responses. For multi-response optimization, Taguchi's quality loss function approach was proposed. Saha and Mandal (2013) investigated multi-response optimization of turning process for an optimal parametric combination to yield the minimum power consumption, surface roughness and frequency of tool vibration using a combination of a Grey relational analysis (GRA). Confirmation test was conducted for the optimal machining parameters to validate the test result. Chakraborty et al. (2013) computed multiple performance measures, e.g. material removal rate (MRR), tool wear rate (TWR), surface roughness (SR) etc., which were affected by several process parameters. Kaladhar et al. (2012) applied Taguchi method to determine the optimum process parameters for turning of AISI 304 austenitic stainless steel on CNC lathe. The influence of these parameters were investigated on the surface roughness and material removal rate (MRR). The Analysis Of Variance (ANOVA) was also used to analyze the influence of cutting parameters during machining (Kumar et al., 2013). Jangra (2012) presented a study on un-machined surface area named as surface projection, in die cutting after rough cut in WEDM process. Jangra et al. (2011) studied wire electrical discharge machining of WCCo composite. Influence of taper angle, peak current, pulse-on time, pulse-off time, wire tension and dielectric flow rate are investigated for material removal rate (MRR) and surface roughness (SR) during intricate machining of a carbide block. In order to optimize MRR and SR simultaneously, grey relational analysis (GRA) was employed along with Taguchi method.

The objective of the present work is to study the characteristic features of the EDM process as reflected through Taguchi design based experimental studies with various process parametric combinations like Gap Current (GI), Pulse on Time (POT), Pulse off Time (POF) \& Spark Gap (SG) on Material removal Rate (MRR), Surface Roughness (Ra) \& Overcut (OC). Initially nine experimental runs are conducted where the significant process parameters are identified using Analysis of Variance (ANOVA) (Bose et al., 2011). The objective being conflicting in nature, it is very difficult to achieve them simultaneously by a single set of process variables. In the present work, Grey Relational Analysis (GRA) technique is attempted to establish a set of process variables that yields high MRR but simultaneously keeps the Surface roughness (Ra) and Overcut (OC) reasonably low (Bose \& Mitra, 2013). In order to achieve this 27 experimental runs are performed for simultaneous optimization of the responses.

\section{Planning for experimentation}

In the present research work Electric Discharge Machine (ACTSPARK SP1, China) die-sinking type with servo-head (constant gap) and positive polarity for electrode is used for experimentation. 
Commercial grade EDM-30 oil (specific gravity=0.80 at $25^{\circ} \mathrm{C}$, Viscosity of $3.11 \mathrm{CSt}$ @ $100^{\circ} \mathrm{F}\left(38^{\circ} \mathrm{C}\right)$ ) was used as dielectric fluid. With external lateral flushing using a square-shaped $\mathrm{Cu}$ tool $(12 \times 12 \mathrm{~mm})$ having a pressure $0.2 \mathrm{kgf} / \mathrm{cm}^{2}$ is used. Experiments were conducted with positive polarity of electrode. AISI H-13 Tool steel work piece material is selected for the experiment. The pulsed discharge current was applied in various steps in positive mode. The EDM setup consists of dielectric reservoir, pump and circulation system, power generator and control unit, working tank with work holding device, X-Y table accommodating the working table, tool holder, the servo system to feed the tool part as shown in Fig. 1.

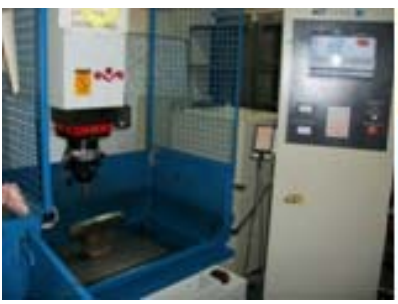

(a)

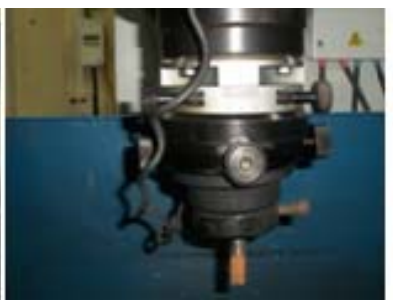

(b)

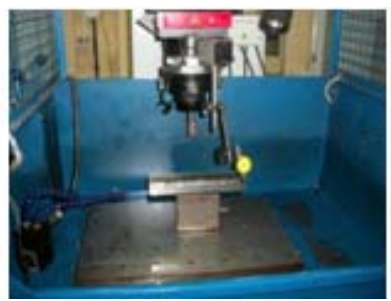

(c)

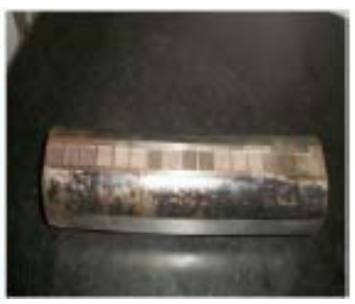

(d)

Fig. 1. (a) Working Tank with work holding (b) Tool holding devices (c) Tool holder (d) Work piece

The servo control unit is provided to maintain the pre-determined gap. It senses the gap voltage and compares it with the current value and the difference in voltage is then used to control the movement of servo motor to adjust the gap. The MRR is expressed as the ratio of the volume of the work piece material removed during machining the cavity to the machining time. Surface roughness of the cavity surface is expressed as $\mathrm{Ra}$ in $\mu \mathrm{m}$, is measured using stylus type profilometer named Talysurf (Taylor's Hobson Surtronic 3+). Overcut (OC) is articulated as half the difference of area of the cavity produced to the tool frontal area. Area of Cavity \& frontal area of electrode is calculated by measuring the respective length \& width using Toolmaker's microscope. While executing an experiment, varying the levels of the factors simultaneously rather than one at a time is efficient in terms of time and cost and also allows for the study of interactions between the factors. Based on past research works and preliminary investigation, four input parameters are chosen. Initially L9 orthogonal array is employed for the experimentation. The input parameters were varied with three levels in nine experimental run. There are other factors which may affect the measured performance like Duty cycle, Flushing pressure, Lift time, electrode material etc., however, are kept constant during experimentation. Table 1 exhibits the different levels of control parameters during machining process.

Table 1

Parametric settings and responses for experimental run

\begin{tabular}{cccccccc}
\hline \multicolumn{4}{c}{ Control Parameters } & \multicolumn{3}{c}{ Responses } \\
\hline Expt. No. & $\begin{array}{c}\text { POT } \\
(\mu \mathrm{Sec})\end{array}$ & $\begin{array}{c}\text { POF } \\
(\mu \mathrm{Sec})\end{array}$ & $\begin{array}{c}\text { GI } \\
(\mathrm{Amp})\end{array}$ & $\mathrm{SG}(\mathrm{mm})$ & $\begin{array}{c}\text { MRR } \\
\left(\mathrm{mm}^{3} / \mathrm{Sec}\right)\end{array}$ & $\begin{array}{c}\text { Ra } \\
(\mu \mathrm{mm})\end{array}$ & $\begin{array}{c}\text { OC } \\
\left(\mathrm{mm}^{2}\right)\end{array}$ \\
\hline 1 & 16 & 12 & 7 & 0.16 & 0.0346 & 9.6 & 4.237 \\
2 & 16 & 16 & 9 & 0.18 & 0.0933 & 10.733 & 2.358 \\
3 & 16 & 20 & 11 & 0.2 & 0.1441 & 11.133 & 3.556 \\
4 & 20 & 12 & 9 & 0.2 & 0.1581 & 7.6 & 4.469 \\
5 & 20 & 16 & 11 & 0.16 & 0.2064 & 9.4 & 4.349 \\
6 & 20 & 20 & 7 & 0.18 & 0.0133 & 6.6 & 3.376 \\
7 & 24 & 12 & 11 & 0.18 & 0.1267 & 7.93 & 3.241 \\
8 & 24 & 16 & 7 & 0.2 & 0.0085 & 3.467 & 3.124 \\
9 & 24 & 20 & 9 & 0.16 & 0.0943 & 9.2 & 4.876 \\
\hline
\end{tabular}

\section{Results analysis using ANOVA}

The parametric design is a significant and controlling tool that employs the Taguchi philosophy for the design of robust, high class systems implementation. It is a competent and systematic modus operandi 
for optimizing the performance characteristics of a system through setting of design parameters. In this approach, the sensitivity of the system performance to sources of variation is reduced through the selection of optimal values of relevant process parameters. The fundamental principle of robust design is to improve the quality of a product by minimizing the effect of the causes of variation, without eliminating the causes (Phadke, 1989). This can be achieved by optimizing the product and process, making its performance minimally sensitive to the various causes of variation. ANOVA is a functional method for estimating error variance and determining the relative importance of various process variables (Ross, 2005). The experimental outcomes are explored to study the role of different process variables on various responses by applying $\mathrm{S} / \mathrm{N}$ ratio and ANOVA. The result analysis is carried out by statistical software MINITAB, version 13.

\subsection{Analysis of test results}

$\mathrm{S} / \mathrm{N}$ ratio determines the contribution of different process variables on various responses. The goal is to find out an optimal combination of control factor settings that achieve robustness against (insensitivity to) noise factors. S/N ratio analysis for MRR $\left(\mathrm{mm}^{3} / \mathrm{min}\right)$ is carried out on the basis of larger is the better and the corresponding $\mathrm{S} / \mathrm{N}$ ratio is expressed as follows:

$n_{1=-10 \log _{10}\left[1 / n \sum_{i=1}^{n} 1 / M R R^{2}\right]}$

$\mathrm{S} / \mathrm{N}$ ratio analysis for $\mathrm{Ra}$ is modeled on the basis of smaller is the better and corresponding equation is

$n_{2=-10 \log _{10}\left[1 / n \sum_{i=1}^{n} R a^{2}\right]}$

$\mathrm{S} / \mathrm{N}$ ratio analysis for $\mathrm{OC}$ is represented on the basis of smaller is the better and corresponding equation is

$n_{3=-10 \log _{10}\left[1 / n \sum_{i=1}^{n} O C^{2}\right]}$

\subsubsection{Analysis of test results for MRR}

The Signal to noise ratio $(\mathrm{S} / \mathrm{N})$ analysis for MRR $(\mathrm{gm} / \mathrm{min})$ is conducted on the basis of larger is the better option. The $\mathrm{S} / \mathrm{N}$ ratio for MRR is shown in Table 2.

Table 2

Signal to Noise (S/N) Ratio for MRR

\begin{tabular}{ccccc}
\hline Level & POT & POF & GI & SG \\
\hline 1 & -22.2129 & -21.0589 & -36.0656 & -21.1422 \\
2 & -22.4167 & -25.2570 & -19.0445 & -25.3566 \\
3 & -26.6390 & -24.9527 & -16.1586 & -24.7699 \\
Delta & 4.4261 & 4.1981 & 19.9070 & 4.2144 \\
Rank & 2 & 4 & 1 & 3 \\
\hline
\end{tabular}

Based on the Delta value as mentioned in the above table, it is observed that gap current (GI) and Pulse on Time (POT) rank 1 and 2 respectively that are followed by spark gap (SG) and Pulse off Time (POF). It is observed that MRR is maximum at the parametric combination of $\mathrm{POT}_{1}-\mathrm{POF}_{1}-\mathrm{GI}_{3}-$ $\mathrm{SG}_{1}$. Table 3 shows the ANOVA results for MRR. ANOVA results as exhibited from F-values and \% contribution of the process variables states that the F values of Gap current assume value 22.337 with a yield of $82.28 \%$ in case of MRR. This implies that the variable have significant effects on MRR in contrast to the other three parameters. The $\mathrm{S} / \mathrm{N}$ ratio plot for MRR is shown in Fig. 2. It is observed from the $\mathrm{S} / \mathrm{N}$ ratio graph that the MRR attains its peak with the parametric combination of POT (16 $\mu \mathrm{Sec})$, POF (12 $\mu \mathrm{sec})$, GI (11 amp), SG (0.16 mm). 
Table 3

Analysis of Variance for MRR

\begin{tabular}{ccccccc}
\hline Source & DF & Seq SS & Adj SS & Adj MS & F - value & \% Contribution \\
\hline POT & 2 & 0.0038895 & 0.0038895 & 0.0019448 & 2.811 & 10.35 \\
POF & 2 & 0.0008774 & 0.0008774 & 0.0004387 & 0.6342 & 2.33 \\
GI & 2 & 0.0309011 & 0.0309011 & 0.0154505 & $\mathbf{2 2 . 3 3 7}$ & $\mathbf{8 2 . 2 8}$ \\
SG & 2 & 0.0018894 & 0.0018894 & 0.0009447 & 1.366 & 5.03 \\
Error & 0 & 0.0000000 & 0.0000000 & 0.0000000 & & \\
Total & 8 & 0.0375573 & & & & \\
Pooled Error & $(4)$ & $(0.0027668)$ & & 0.0006917 & & \\
\hline
\end{tabular}

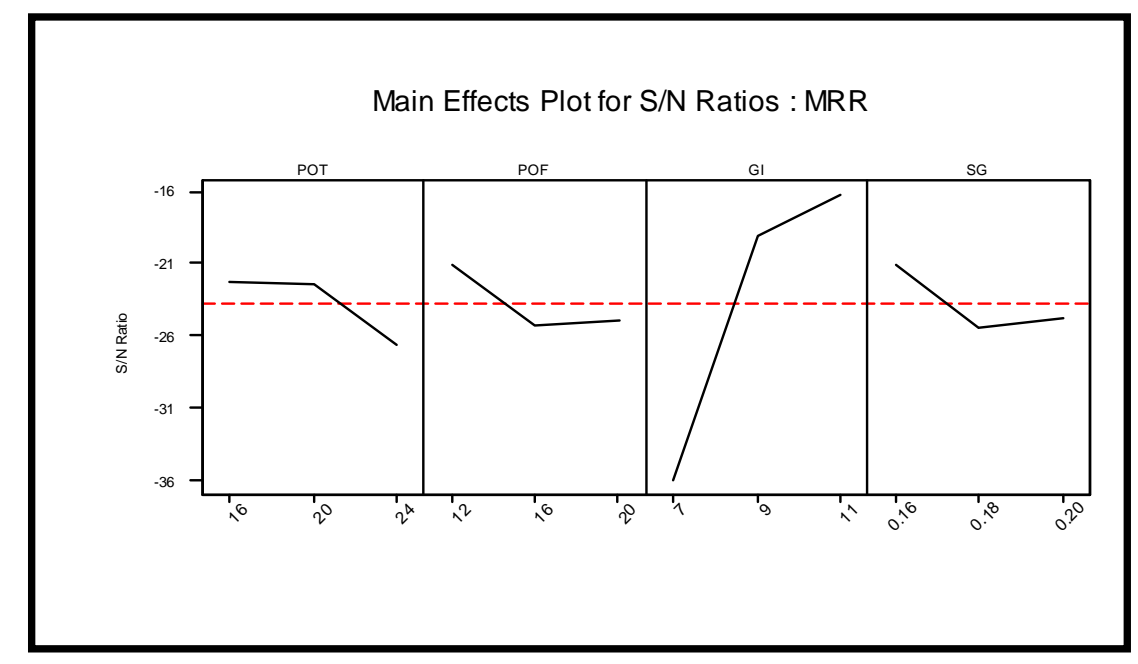

Fig. 2. $\mathrm{S} / \mathrm{N}$ ratio plot for $\mathrm{MRR}$

\subsubsection{Analysis of test results for $\mathrm{Ra}$}

The Signal to noise ratio $(\mathrm{S} / \mathrm{N})$ analysis for $\mathrm{Ra}$ is modeled on the basis of smaller is the better. The $\mathrm{S} / \mathrm{N}$ ratio for $\mathrm{Ra}$ is shown in Table 4.

Table 4

Signal to Noise (S/N) Ratio for Ra

\begin{tabular}{|c|c|c|c|c|}
\hline Level & POT & POF & GI & $\mathrm{SG}$ \\
\hline 1 & -20.6843 & -18.7026 & -15.8984 & -20.5501 \\
\hline 2 & -18.6252 & -17.7605 & -19.1689 & -18.3303 \\
\hline 3 & -16.0198 & -18.8663 & -20.2620 & -16.4489 \\
\hline Delta & 4.6645 & 1.1058 & 4.3636 & 4.1012 \\
\hline Rank & 1 & 4 & 2 & 3 \\
\hline
\end{tabular}

Based on the Delta value as mentioned in the above table it is observed that Pulse on Time (POT) and gap current (GI) rank 1 and 2 respectively that are followed by spark gap (SG) and Pulse off Time (POF). It is observed that $\mathrm{Ra}$ is minimum at the parametric combination of $\mathrm{POT}_{3}-\mathrm{POF}_{2}-\mathrm{GI}_{1}-\mathrm{SG}_{3}$. Table 5 shows the ANOVA results for Ra.

\section{Table 5}

Analysis of Variance for Ra

\begin{tabular}{ccccccc}
\hline Source & DF & Seq SS & Adj SS & Adj MS & F- Value & \% Contribution \\
\hline POT & 2 & 21.0052 & 21.0052 & 10.5026 & 5.34 & 47.24 \\
POF & 2 & 1.8556 & 1.8556 & 0.9278 & 0.472 & 3.17 \\
GI & 2 & 15.5692 & 15.5692 & 7.7846 & 3.963 & 1.527 \\
SG & 2 & 6.0015 & 6.0015 & 3.0007 & & 13.5 \\
Error & 0 & 0.0000 & 0.0000 & 0.0000 & & \\
Total & 8 & 44.4315 & & & & $(1.9643)$ \\
Pooled Error & $(4)$ & $(7.8571)$ & & & \\
\hline
\end{tabular}


In case of Ra, Pulse on Time (POT) alone is the major contributor having F value of healthy 5.34 and having \% contribution of 47.24, which is widely followed by Gap Current having $\mathrm{F}$ value of approximately 4 . The other parameters behave insignificantly for the response. The $\mathrm{S} / \mathrm{N}$ ratio plot for $\mathrm{Ra}$ is shown in Fig. 3.

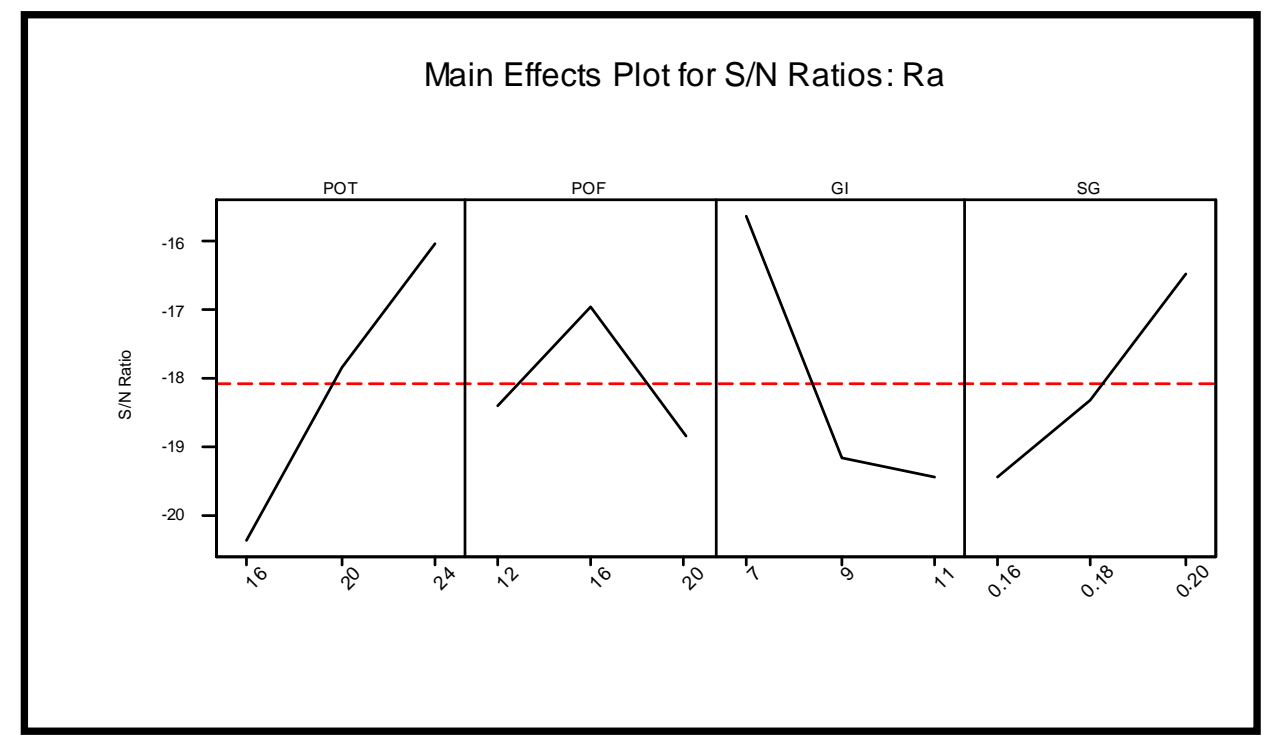

Fig. 3. S/N ratio plot for $\mathrm{Ra}$

It is observed from the $\mathrm{S} / \mathrm{N}$ ratio plot for smaller is better in case of $\mathrm{Ra}$ is obtained at POT $(24 \mu \mathrm{Sec})$, POF (16 $\mu \mathrm{sec})$, GI (7 amp), SG (0.20mm).

\subsection{Analysis of test results for OC}

The Signal to noise ratio $(\mathrm{S} / \mathrm{N})$ analysis for $\mathrm{OC}$ is represented on the basis of smaller is the better. The $\mathrm{S} / \mathrm{N}$ ratio for OC is shown in Table 6.

Table 6

Signal to Noise (S/N) Ratio for OC

\begin{tabular}{ccccc}
\hline Level & POT & POF & GI & SG \\
\hline 1 & -10.3366 & -11.9193 & -11.0009 & -13.0230 \\
2 & -12.1130 & -10.0372 & -11.4049 & -9.4108 \\
3 & -11.2899 & -11.7829 & -11.3336 & -11.3056 \\
Delta & 1.7764 & 1.8820 & 0.4041 & 3.6122 \\
Rank & 3 & 2 & 4 & 1 \\
\hline
\end{tabular}

Based on the Delta value as mentioned in the above table it is observed that Spark Gap (SG) and Pulse off Time (POF) rank 1 and 2 respectively that are followed by Pulse on Time (POT) and Gap Current (GI). It is observed that $\mathrm{OC}$ is minimum at the parametric combination of $\mathrm{POT}_{1}-\mathrm{POF}_{2}-\mathrm{GI}_{1}-\mathrm{SG}_{2}$. Table 7 represents the ANOVA findings for OC.

\section{Table 5}

\begin{tabular}{ccccccc}
\multicolumn{2}{l}{ Analysis of Variance for OC } & \multicolumn{1}{l}{} \\
\hline Source & DF & Seq SS & Adj SS & Adj MS & F - value & \% Contribution \\
\hline POT & 2 & 0.69671 & 0.69671 & 0.34835 & 0.816 & 13.4 \\
POF & 2 & 0.93399 & 0.93399 & 0.46699 & 1.094 & 17.95 \\
GI & 2 & 0.15666 & 0.15666 & 0.07833 & 0.183 & 2.6 \\
SG & 2 & 3.35571 & 3.35571 & 1.67785 & $\mathbf{4 . 0}$ & $\mathbf{6 5 . 6}$ \\
Error & 0 & 0 & 0 & 0 & & \\
Total & 8 & 5.14306 & & & & \\
Pooled error & 4 & 0.85337 & & 0.426685 & & \\
\hline
\end{tabular}


In case of Overcut the Spark Gap (SG) alone is the major contributor having F value of healthy 4.0 with \% contribution of 65.60 . Other factors here remain insignificant. The $\mathrm{S} / \mathrm{N}$ ratio plot for $\mathrm{OC}$ is shown in Fig. 4.

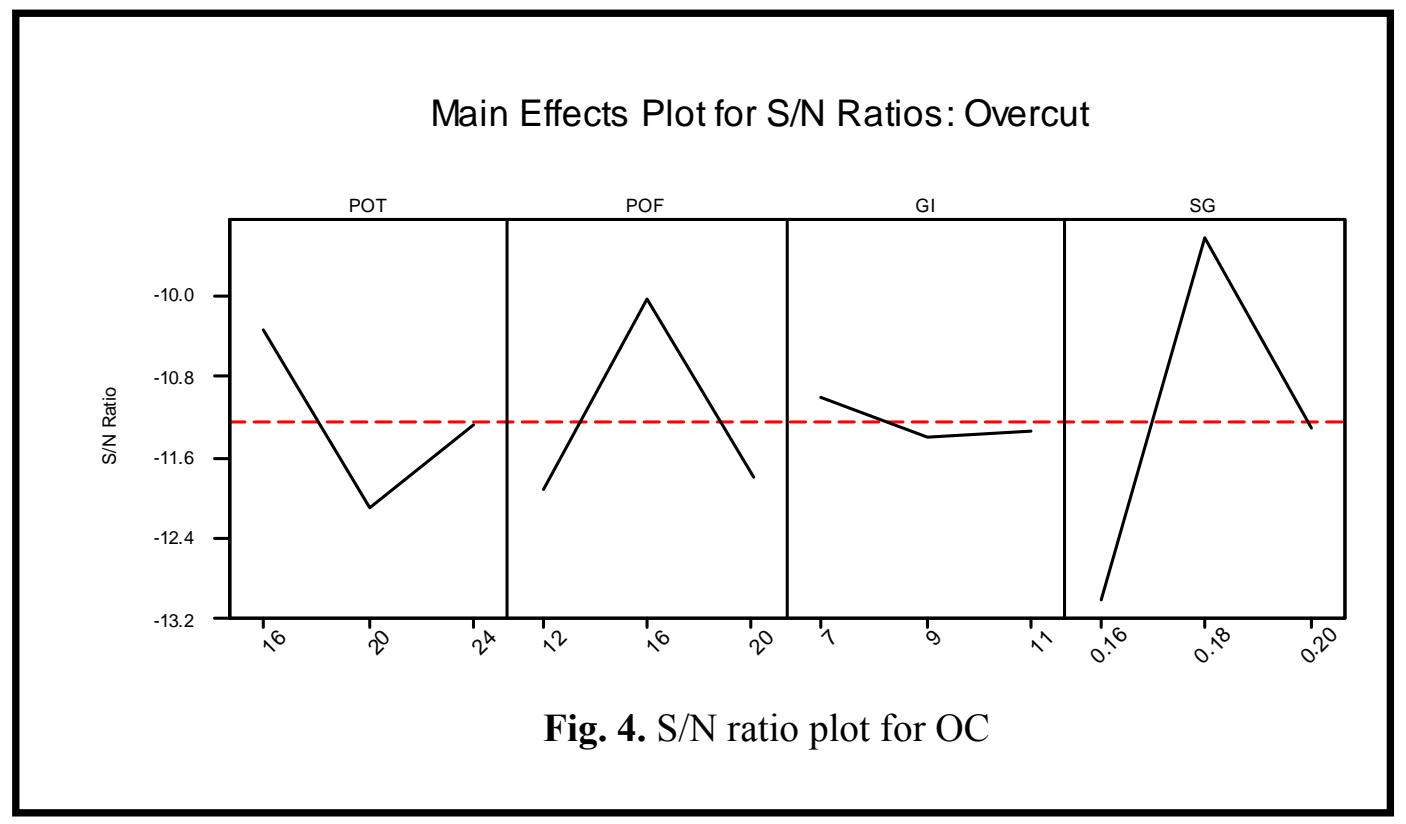

It is seen from the $\mathrm{S} / \mathrm{N}$ ratio plot that for smaller is better for $\mathrm{OC}$ is obtained at POT $(16 \mu \mathrm{Sec})$, POF (16 $\mu \mathrm{sec})$, GI (7 amp), SG $(0.18 \mathrm{~mm})$.

\section{Multi-Objective model using Grey Relational Analysis}

The modus operandi of Grey Relational Analysis (GRA) at the outset is converting the performance of all alternatives into a comparability sequence (Deng, 1989). This step is known as grey relational creating. According to these sequences, an ideal target sequence is defined. Then, the grey relational coefficient between all comparability sequences and the reference sequence is calculated. Finally, based on these grey relational coefficients, the grey relational grade between the reference sequence and every comparability sequences is calculated. If a comparability sequence translated from an alternative has the highest grey relational grade between the reference sequence and itself, that alternative will be the most excellent choice.

If the range and unit in one data sequence of a response parameter differ from the others then data preprocessing in GRA is required. If the sequence range is excessively large and the standard value is too high, then the effect of some factors needs to be ignored. The process of transferring the original data sequence to a comparable sequence is called normalization. The original data are normalized into the range between zero and one. If higher value indicates the better performance such as MRR then it is normalized as per equation,

$$
X_{i j}=\frac{Y_{i j-} \operatorname{Min}\left[Y_{i j}, i=1,2, \ldots n\right]}{\operatorname{Max}\left[Y_{i j}, i=1,2 \ldots n\right]-\operatorname{Min}\left[Y_{i j}, i=1,2, \ldots n\right]}
$$

If lower value indicates better performance such as $\mathrm{R}_{\mathrm{a}}$ and $\mathrm{OC}$ then it is expressed as,

$$
X_{i j}=\frac{\operatorname{Max}\left[Y_{i j}, i=1,2, \ldots n\right]-Y_{i j}}{\operatorname{Max}\left[Y_{i j}, i-1,2, \ldots n\right]-\operatorname{Min}\left[Y_{i j}, i=1,2, \ldots n\right]}
$$


The grey relational coefficient is determined to express the relationship between reference and actual normalized experimental data. Reference data is the best data which is expressed as $X_{0}$. The grey relational coefficient can be calculated as:

$Y\left(X_{o j}, X_{i j}\right)=\frac{\nabla_{\min }+\zeta \nabla_{\max }}{\nabla_{i j}+\zeta \nabla_{\max }}[i=1,2, \ldots n \& j=1,2, \ldots m]$,

where, $\nabla_{i j}=\left|X_{o j}-X_{i j}\right|, \nabla_{\min }=\operatorname{Min}\left|\nabla_{i j}, i=1,2, \ldots n \& j=1,2, \ldots m\right|$ and $\left.\quad \nabla_{\max }=\operatorname{Max} \mid \nabla_{i j}, i=1,2, \ldots n \& j=1,2, \ldots m\right], \quad \zeta \quad$ is the distinguishing coefficient that is defined in the range between 0 to 1 . Generally, the distinguishing coefficient can be adjusted to fit the practical requirements. The grey relational grade can be determined as the average of the grey relational coefficients associated with each response parameter. It can be expressed as follows:

$\Gamma\left(X_{o}, X_{i}\right)=\frac{1}{m} \sum_{j=1}^{m} Y\left(X_{o j}, X_{i j}\right)$,

where, $\mathrm{m}$ is the number of response parameter.

\subsection{Weight calculation by Entropy method}

Entropy method is one of the well-known and widely used methods to calculate the criteria decision weights. Decision weights increases the importance of criteria and is usually categorized into two types. One is subjective weight, determined by the knowledge and experience of experts or individuals, and the other is objective weight, determined mathematically by analyzing the collected data. Here Entropy weight is objective weight and can be determined by following steps, (Ding and Shi, 2005):

Step 1: Formation of Decision Matrix (D): Decision matrix $(D)$ with $m$ alternatives and $n$ criteria is composed as shown in equation below:

$$
\begin{aligned}
& \begin{array}{rll}
\text { Alternatives } & & \text { Criteria } \rightarrow \\
\downarrow C_{1} & C_{j} \quad C_{n}
\end{array} \\
& D=A_{i} A_{1}\left[\begin{array}{ccccc}
d_{11} & \ldots & d_{1 j} & \ldots & d_{1 n} \\
\vdots & A_{m}
\end{array}\left[\begin{array}{ccccc}
d_{i 1} & \cdots & d_{i j} & \cdots & d_{i n} \\
\vdots & \cdots & \vdots & \cdots & \vdots \\
d_{m 1} & \cdots & d_{m j} & \cdots & d_{m n}
\end{array}\right]\right.
\end{aligned}
$$

\section{Step 2: Formation of Normalized Decision Matrix $\left(\bar{D}_{i j}\right)$ :}

In matrix $D, d_{i j}$ is of the $i^{\text {th }}$ alternatives to the $j^{\text {th }}$ factor:

$\bar{d}_{i j}=\frac{d_{i j}}{\sum_{i=1}^{m} d_{i j}} \quad(1 \leq i \leq n, \quad 1 \leq j \leq m)$

\section{Step 3: Calculation of output Entropy $\left(e_{j}\right)$ :}

The output entropy $e_{j}$ of the $\mathrm{j}^{\text {th }}$ factor becomes

$e_{j}=-\frac{1}{\ln m} \sum_{i=1}^{m} a_{i j} \ln a_{i j}$ 
Step 4: Computation of the Weight $\left(w_{j}\right)$ :

Weight of $j^{\text {th }}$ criterion $\left(w_{j}\right)$ is as follow.

$w_{j}=\frac{1-e_{j}}{\sum_{j=1}^{n}\left(1-e_{j}\right)}$

where, $\sum_{j=1}^{n} w_{j}=1$ and $\left(1-e_{j}\right)$ is called uncertainty

\subsection{Multi Criteria Decision Making Analysis}

In relation to the present work, the three responses i.e. MRR, Ra and Overcut have got different level of importance. In this Die sinking EDM operation, emphasis is given on MRR rather than on Ra and OC leading to an assignment of unequal weights to the three attributes. In this experimentation $87 \%, 7 \%$ and $6 \%$ weights are assigned to MRR, Ra and OC respectively as calculated from Entropy method. Generally, a high value of the grey relational grade corresponds to a strong relation between the reference data sequence and the comparative sequence. As mentioned above, the reference data is the best response of the experimental results. Therefore, a higher value of the grey relational grade means that the corresponding machining parameters are closer to the optimal levels. In other words, the optimization of machining parameters associated with the complex multiple response parameters can be converted into the optimal resolution of single grey relational grade. The decision matrix used for Entropy method and GRA is shown in table 6 below. Here 27 experimental runs are conducted based on Box-Behenken Design with the control parameters for determining the three responses (Jana et al., 2011). In the problem, a decision matrix is formed consisting of nine alternatives and four criteria, i.e. $m=27$ and $n=3$. The MRR is considered to be maximum i.e. higher the better and other criteria are considered minimum, i.e. lower is better.

Table 6

Combination of factors and responses

\begin{tabular}{|c|c|c|c|c|c|c|c|}
\hline EXPT NO. & $\begin{array}{c}\text { POT } \\
(\mu \text { Sec })\end{array}$ & $\begin{array}{c}\text { POF } \\
(\mu \mathrm{Sec})\end{array}$ & $\begin{array}{c}\text { GI } \\
\text { (Amp) }\end{array}$ & $\begin{array}{c}\mathrm{SG} \\
(\mathrm{mm})\end{array}$ & $\begin{array}{c}\text { MRR } \\
\left(\mathrm{mm}^{3} / \mathrm{Sec}\right)\end{array}$ & $\underset{(\mu \mathrm{mm})}{\mathbf{R a}}$ & $\begin{array}{c}\text { Overcut } \\
\left(\mathrm{mm}^{2}\right)\end{array}$ \\
\hline 1 & 20 & 12 & 11 & 0.18 & 1.2578 & 9.467 & 2.529 \\
\hline 2 & 24 & 20 & 9 & 0.18 & 0.1572 & 2.067 & 3.498 \\
\hline 3 & 24 & 16 & 11 & 0.18 & 0.832 & 7.6 & 5.3177 \\
\hline 4 & 20 & 20 & 7 & 0.18 & 0.0956 & 2.267 & 2.7668 \\
\hline 5 & 16 & 16 & 11 & 0.18 & 2.0271 & 9.067 & 2.892 \\
\hline 6 & 20 & 16 & 7 & 0.16 & 0.07652 & 5.467 & 3.739 \\
\hline 7 & 16 & 20 & 9 & 0.18 & 0.4193 & 7.733 & 4.9574 \\
\hline 8 & 20 & 20 & 11 & 0.18 & 1.1941 & 11.367 & 5.6864 \\
\hline 9 & 20 & 16 & 11 & 0.2 & 1.6 & 12.667 & 5.2014 \\
\hline 10 & 24 & 16 & 9 & 0.16 & 0.0969 & 3.067 & 3.4982 \\
\hline 11 & 20 & 16 & 9 & 0.18 & 0.0479 & 11.467 & 3.2556 \\
\hline 12 & 16 & 16 & 7 & 0.18 & 0.0367 & 8.133 & 2.166 \\
\hline 13 & 20 & 12 & 9 & 0.2 & 0.1581 & 7.6 & 4.4686 \\
\hline 14 & 16 & 16 & 9 & 0.16 & 0.17158 & 8.867 & 3.376 \\
\hline 15 & 20 & 16 & 9 & 0.18 & 0.1383 & 8.867 & 4.5915 \\
\hline 16 & 20 & 16 & 11 & 0.16 & 0.2064 & 9.4 & 4.3488 \\
\hline 17 & 20 & 20 & 9 & 0.16 & 0.08905 & 9.467 & 2.2852 \\
\hline 20 & 20 & 12 & 9 & 0.16 & 0.0773 & 9.333 & 1.4424 \\
\hline 21 & 20 & 16 & 7 & 0.2 & 0.00877 & 8 & 1.6827 \\
\hline 22 & 16 & 16 & 9 & 0.2 & 0.0892 & 11.6 & 2.8896 \\
\hline 23 & 16 & 12 & 9 & 0.18 & 0.17357 & 9.867 & 2.0444 \\
\hline 24 & 24 & 12 & 9 & 0.18 & 0.0324 & 3.933 & 1.9248 \\
\hline 25 & 24 & 16 & 9 & 0.2 & 0.116 & 11.733 & 3.6187 \\
\hline 26 & 24 & 16 & 7 & 0.18 & 0.00636 & 5.333 & 3.498 \\
\hline 27 & 20 & 12 & 7 & 0.18 & 0.01333 & 6.6 & 3.376 \\
\hline
\end{tabular}

Table 7 presents the results of grey relational coefficients, grey relational grades, and their ranks. The results show that experiment number 24 has the largest grey relational grade. Therefore, it is expected 
that the machining parameter setting of this experiment will fulfill multiple response parameters optimization. Therefore experimental run of 24 having parametric combination POT (24), POF (12), GI (9) and SG (0.18) suffice for having high MRR, low Ra and low OC respectively.

\section{Table 7}

Grey relational coefficients and grades

\begin{tabular}{|c|c|c|c|c|c|c|c|c|}
\hline \multirow{2}{*}{$\begin{array}{l}\text { Expt. } \\
\text { No. }\end{array}$} & \multicolumn{3}{|c|}{ Normalizing } & \multicolumn{3}{|c|}{ Grey Coefficient } & \multirow{2}{*}{ Grey Grade } & \multirow[t]{2}{*}{ Rank } \\
\hline & MRR & Ra & OC & MRR & $\mathbf{R a}$ & OC & & \\
\hline 1 & 0.6192979 & 0.3018868 & 0.743968 & 0.995643 & 0.909314 & 0.959074 & 0.954677 & 11 \\
\hline 2 & 0.0746459 & 1 & 0.5156456 & 0.989476 & 1 & 0.925304 & 0.971593 & 3 \\
\hline 3 & 0.408583 & 0.4780189 & 0.0868756 & 0.993248 & 0.930606 & 0.867914 & 0.930589 & 24 \\
\hline 4 & 0.044162 & 0.9811321 & 0.6879359 & 0.989133 & 0.997312 & 0.950561 & 0.979002 & 2 \\
\hline 5 & 1 & 0.3396226 & 0.6584354 & 1 & 0.913793 & 0.946139 & 0.953311 & 14 \\
\hline 6 & 0.03472 & 0.6792453 & 0.4588596 & 0.989027 & 0.956186 & 0.917271 & 0.954161 & 12 \\
\hline 7 & 0.2043509 & 0.4654717 & 0.1717719 & 0.990937 & 0.929056 & 0.878705 & 0.9329 & 20 \\
\hline 8 & 0.5877748 & 0.1226415 & 0 & 0.995284 & 0.888623 & 0.857143 & 0.913683 & 27 \\
\hline 9 & 0.7886418 & 0 & 0.114279 & 0.997576 & 0.875 & 0.871368 & 0.914648 & 26 \\
\hline 10 & 0.0448054 & 0.9056604 & 0.5155985 & 0.98914 & 0.986702 & 0.925297 & 0.967047 & 5 \\
\hline 11 & 0.0205568 & 0.1132075 & 0.5727615 & 0.988867 & 0.88756 & 0.933527 & 0.936651 & 19 \\
\hline 12 & 0.0150143 & 0.4277358 & 0.8295005 & 0.988805 & 0.924426 & 0.972369 & 0.961867 & 7 \\
\hline 13 & 0.0750913 & 0.4780189 & 0.2869463 & 0.989481 & 0.930606 & 0.893781 & 0.937956 & 18 \\
\hline 14 & 0.0817621 & 0.3584906 & 0.5443921 & 0.989556 & 0.916049 & 0.929424 & 0.94501 & 16 \\
\hline 15 & 0.0652929 & 0.3584906 & 0.2579877 & 0.98937 & 0.916049 & 0.889942 & 0.931787 & 22 \\
\hline 16 & 0.0989934 & 0.3082075 & 0.3151744 & 0.98975 & 0.910061 & 0.897555 & 0.932455 & 21 \\
\hline 17 & 0.0409207 & 0.3018868 & 0.8014138 & 0.989096 & 0.909314 & 0.967963 & 0.955458 & 10 \\
\hline 18 & 0.0438651 & 0.3773585 & 0.5732328 & 0.989129 & 0.918317 & 0.933595 & 0.947014 & 15 \\
\hline 19 & 0.035007 & 0.3145283 & 0.0565975 & 0.98903 & 0.910809 & 0.86413 & 0.921323 & 25 \\
\hline 20 & 0.035106 & 0.3145283 & 1 & 0.989031 & 0.910809 & 1 & 0.966613 & 6 \\
\hline 21 & 0.0011926 & 0.440283 & 0.9433789 & 0.98865 & 0.925961 & 0.990651 & 0.968421 & 4 \\
\hline 22 & 0.0409949 & 0.1006604 & 0.6590009 & 0.989097 & 0.88615 & 0.946223 & 0.94049 & 17 \\
\hline 23 & 0.0827469 & 0.2641509 & 0.8581527 & 0.989567 & 0.904878 & 0.976905 & 0.957117 & 9 \\
\hline 24 & 0.0128864 & 0.8239623 & 0.8863336 & 0.988781 & 0.975469 & 0.981408 & 0.981886 & 1 \\
\hline 25 & 0.0542574 & 0.0881132 & 0.4872055 & 0.989246 & 0.884745 & 0.921264 & 0.931752 & 23 \\
\hline 26 & 0 & 0.6918868 & 0.5156456 & 0.988636 & 0.95784 & 0.925304 & 0.95726 & 8 \\
\hline 27 & 0.0034492 & 0.5723585 & 0.5443921 & 0.988675 & 0.942426 & 0.929424 & 0.953508 & 13 \\
\hline
\end{tabular}

The grade corresponding to each control factor at their levels are calculated as shown in Table 8 and subsequently the overall mean is calculated. Then the absolute value, which is the difference between the maximum and minimum value of each factor considering different levels of grey relational grade is computed. The optimum level setting for the control factor is selected corresponding to the maximum value of the level of each factor. Total mean value of the grey relational grade is 0.948081

Table 8

Response table for determination of optimum level setting

\begin{tabular}{cccccc}
\hline Factors & Level 1 & Level 2 & Level 3 & ABS & Rank \\
\hline POT & 0.948449 & 0.944491 & $\mathbf{0 . 9 5 6 6 8 8}$ & 0.012197 & 4 \\
POF & $\mathbf{0 . 9 5 8 6 2 6}$ & 0.944831 & 0.94566 & 0.013795 & 3 \\
GI & $\mathbf{0 . 9 6 2 3 7}$ & 0.948306 & 0.933227 & 0.029143 & 1 \\
SG & $\mathbf{0 . 9 5 3 4 5 7}$ & 0.950856 & 0.935765 & 0.017692 & 2 \\
\hline
\end{tabular}

Total mean value of the grey relational grade $=0.948081$

Fig. 5 shows the grey relational grade graph, where the dashed line in this figure is the value of the total mean of the grey relational grade. The larger the grey relational grade, the better are the multiple performance characteristics. However, the relative importance among the process parameters for the multiple performance characteristics still needs to be known, so that the optimal combinations of the process parameter levels can be determined. The grey relational grade graph that manifests that best combination is $\mathrm{POT}_{3}-\mathrm{POF}_{1}-\mathrm{GI}_{1}-\mathrm{SG}_{1}$. The confirmation experiment performed with the above combination results in grey relational grade of 0.980832 having MRR, Ra and OC as 0.0331, 4.1 and 1.952 respectively. It is found that MRR, Ra and OC improve considerably (as evident from computational results) by using optimal machining variables combinations. Once the optimal level of 
the machining parameters is selected, the final step is to predict and verify the improvement of the performance characteristic using the optimal level of the machining parameters. Table 8 shows the results of the confirmation experiment employing the optimal machining parameters.

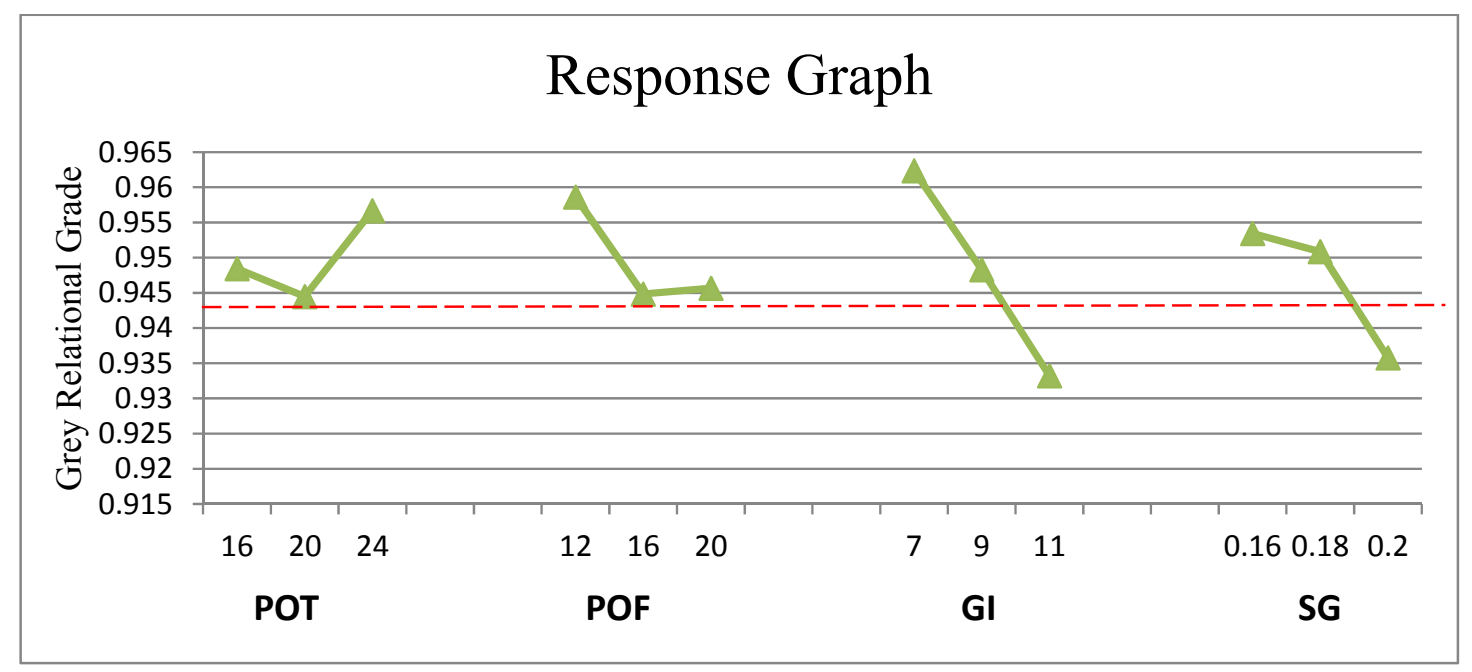

Fig. 5. Grey Relational Grades

Table 8

Results of machining performance using the initial and optimal machining parameters

\begin{tabular}{cccc}
\hline & \multirow{2}{*}{ Initial machining parameters } & \multicolumn{2}{c}{ Optimal machining parameters } \\
\cline { 3 - 4 } & & Prediction & Experiment \\
\hline Setting levels & POT - POF - GI - SG & POT - POF - GI - SG & POT - POF - GI - SG \\
\hline MRR & 1.2578 & 0.0324 & 0.0331 \\
Ra & 9.467 & 3.933 & 4.1 \\
OC & 2.529 & 1.9248 & 1.952 \\
Grey relation grade & 0.954677 & 0.981886 & 0.980832 \\
\hline \multicolumn{4}{c}{} \\
\hline
\end{tabular}

\section{Discussion and Conclusions}

The experimental study indicates that while machining AISI H13 tool steel using die sinking EDM process the responses are dependent on Pulse on time, Pulse off time, Gap current and Spark gap. The $\mathrm{S} / \mathrm{N}$ ratio analysis along with ANOVA is a simple method to ascertain implication of several input parameters that administers multiple responses of the process. For higher MRR, GI is the most significant parameter and having contribution of $82.28 \%$. MRR increases with respect to increase of GI. In case of lower Ra, the POT is having the most significant effect and contributes $47.24 \%$. Ra decreases with the increase of POT and however Ra increases with increase of GI. For smaller overcut, SG is the most significant parameter and contributed $65.6 \%$ and OC decreases with the increase of SG initially up to $0.18 \mathrm{~mm}$ then it increases with respect to SG. The grey relational analysis converts optimization of the multiple characteristics into optimization of a single function called grey relational grade, which simplifies the computation. The grey analysis establishes the ranks of output for different variables combinations. It is found that both MRR and $\mathrm{Ra}$ improve considerably (as evident from computational results) by using optimal machining variables combinations. It is concluded that the grey relational analysis is a powerful method to study the effects of different process variables on multiple performance for complex process like Die Sinking EDM process. The experimental investigation approach for evaluating the optimum EDM parametric combination during machining of AISI H13 tool steel materials can act as useful and an efficient guideline for manufacturing of products of similar material. 


\section{References}

Bose, G. K., Jana, T. K., \& Mitra, S. (2011). Identification of the significant process parameters by Taguchi methodology during electrochemical grinding of $\mathrm{Al} 2 \mathrm{O}$ 3/Al? interpenetrating phase composite. International Journal of Computational Materials Science and Surface Engineering, 4(3), 232-246.

Bose, G. K., \& Mitra, S. (2013). Study of ECG process while machining A12O3/Al-IPC using greyTaguchi methodology. Advances in Production Engineering \& Management, 8(1), 41-51.

Chakravorty, R., Gauri, S., \& Chakraborty, S. (2013). Optimization of Multiple Responses of Ultrasonic Machining (USM) Process: A Comparative Study. International Journal of Industrial Engineering Computations, 4(2), 285-296.

Debroy, A., \& Chakraborty, S. (2013). Non-conventional optimization techniques in optimizing nontraditional machining processes: a review. Management Science Letters, 3(1), 23-38.

Deng, J. L. (1989). Introduction to grey system theory. The Journal of grey system, 1(1), 1-24.

Ding, S., \& Shi, Z. (2005). Studies on incident pattern recognition based on information entropy. Journal of Information Science, 31(6), 497-294.

El-Hofy, H. (2005). Advanced Machining Processes. McGraw Hill.

Gupta, M., \& Kumar, S. (2013). Multi-objective optimization of cutting parameters in turning using grey relational analysis. International Journal of Industrial Engineering Computation, 4(4), 547 - 558.

Ghosh, A., \& Mallik, A. K. (1991). Manufacturing Science. Affiliated East-West Press, New Delhi.

Ho. K.H., \& Newman. S.T. (2003). State of art electrical discharge machining (EDM). International Journal of Machine Tools and Manufacturing, 43(13), 1287 - 1300.

Jangra, K. (2012). Study of unmachined area in intricate machining after rough cut in WEDM. International Journal of Industrial Engineering Computation, 3(5), 887 - 892.

Jangra, K., Grover, S., \& Aggarwal, A. (2011). Simultaneous optimization of material removal rate and surface roughness for WEDM of WC-Co composite using grey relational analysis along with Taguchi method. International Journal of Industrial Engineering Computations, 2(3), 479-490.

Jana, T.K., Bose, G.K., Sarkar, B. \& Saha, J. (2011). Multi-objective decision-making in single-pass turning using response surface methodology, International Journal of Computational Materials Science and Surface Engineering, 4(1), 87-108.

Kaladhar, M., Subbaiah, K.V., Rao, C.S. (2012). Parametric optimization during machining of AISI 304 Austenitic Stainless Steel using CVD coated DURATOMIC cutting insert. International Journal of Industrial Engineering Computation, 3(4), 577 - 586.

Kiyak, M. \& Cakir, O. (2007). Examination of machining parameters on surface roughness in EDM tool steel. Journal of Materials Processing Technology, 191(1-3), 141 - 144.

Kumar, R., Sahoo, A., Satyanarayana, K., \& Rao, G. (2013). Some studies on cutting force and temperature in machining Ti-6Al-4V alloy using regression analysis and ANOVA. International Journal of Industrial Engineering Computations, 4(3), 427-436.

Nadam, S.R., Abhilash, D.E., Ranadheer, P., Srinivas, P.L.V., Kumar, R.S., \& Rao, A. A. (2012). An Experimental investigation on machining of D2 tool steel by EDM sinking process. In $4^{\text {th }}$ International $\& 25^{\text {th }}$ All India Manufacturing Technology, Design and Research Conference, 505 - 512.

Phadke, M. S. (1989). Quality Engineering using Robust Design, Prentice Hall, New Jersey.

Ross, P.J. (2005). Taguchi techniques for quality engineering. $2^{\text {nd }}$ edition, Tata Mc Graw Hill.

Saha, A., \& Mandal, N.K. (2013). Optimization of machining parameters of turning operations based on multi performance criteria. International Journal of Industrial Engineering Computation, 4(1), 51 - 60.

Sahoo, A. K., Mohanty, T. (2013). Optimization of multiple performance characteristics in turning using Taguchi's quality loss function: An experimental investigation. International Journal of Industrial Engineering Computation, 4(3), 325 - 336.

Varun, A., Venkaiah, N., \& Kotiveerachari, B. (2012). Multi - objective optimization of powder mixed EDM. In $4^{\text {th }}$ International \& $25^{\text {th }}$ All India Manufacturing Technology, Design and Research Conference (AIMTDR 2012), 453 - 459.

Yan, B. H., Tsai, H.C., \& Huang, F.Y. (2005). The effect of EDM of a dielectric of a urea solution in water on modifying the surface of titanium. International journal of Machine Tools and Manufacturing, 45(2), $194-200$. 